Original Article

\title{
IN-VITRO ANTIMICROBIAL ACTIVITY OF BIOLOGICAL SYNTHESIZED SILVER NANOPARTICLES USING STENOTROPHOMONAS MALTOPHILIA STRAIN NS-24 FROM NON- RHIZOSPHERE SOIL
}

\author{
SREENIVASA NAYAKA, BIDHAYAK CHAKRABORTY, DATTATREYA AIRODGI, MEGHASHYAMA P. BHAT, \\ SHASHIRAJ K. NAGARAJA, PALLAVI S. SWAMY, MUTHURAJ R., HALASWAMY HIREMATH, DHANYAKUMARA S. \\ BASAVARAJAPPA, MARIA REGO
}

P. G. Department of Studies in Botany, Karnatak University, Dharwad, Karnataka, India 580003

Email: sreenivasanayaka06@gmail.com

Received: 24 Feb 2020, Revised and Accepted: 02 Apr 2020

\begin{abstract}
Objective: The present goals of our study were biological synthesis, characterizations of silver nanoparticles, and evaluation of its antimicrobial activity against microbial pathogens like Escherichia coli, Enterococcus faecalis, Streptococcus pneumoniae and Staphylococcus aureus.

Methods: The bacterial Strain NS-24 was isolated on nutrient agar medium and was selected for the synthesis of silver nanoparticles based on its gram-negative characteristics. The characterizations of silver nanoparticles were done by UV-Visible spectroscopy, Atomic Force Microscopy (AFM), High Resolution-Transmission Electron Microscopy (HR-TEM), Scanning Electron Microscopy (SEM) with Energy Dispersive Spectroscopy (EDX), Xray Diffraction (XRD) and Fourier Transform Infrared Spectroscopy (FTIR). Later, the molecular characterization of the Strain NS-24 was done by DNA extraction and 16S rRNA gene sequencing.

Results: The UV-visible spectrophotometric observation of the Strain NS-24 supernatant and $\mathrm{AgNO}_{3}$ solution showed maximum absorbance at 423 $\mathrm{nm}$. The AFM data confirmed that the particles were polydispersed and spherical in shape. Additionally, the FTIR analysis revealed the IR spectral band patterning and TEM analyzes showed the size of biological AgNPs was in the range of $12.56 \mathrm{~nm}$ to $27.32 \mathrm{~nm}$, with an average of $18.06 \mathrm{~nm}$ in size. Further, the 16S rRNA gene sequencing revealed the identity of Strain NS-24 as Stenotrophomonas maltophilia. The antimicrobial activity of AgNPs was studied on different gram-negative and gram-positive bacterial strains like Escherichia coli (MTCC 40), Enterococcus faecalis (MTCC 6845), Streptococcus pneumoniae (MTCC 8874) and Staphylococcus aureus (MTCC 2825), which showed good inhibition of their growth at varying concentrations of AgNPs against all the pathogens.
\end{abstract}

Conclusion: Our findings showed that the synthesized AgNPs from the isolated bacterium was small in size and had profound antibacterial activity against pathogenic micro-organisms.

Keywords: Stenotrophomonas maltophilia, AgNPs, XRD, HR-TEM, AFM, Antimicrobial

(C) 2020 The Authors. Published by Innovare Academic Sciences Pvt Ltd. This is an open access article under the CC BY license (http://creativecommons.org/licenses/by/4.0/ DOI: http://dx.doi.org/10.22159/ijpps.2020v12i5.37257. Journal homepage: https://innovareacademics.in/journals/index.php/ijpps

\section{INTRODUCTION}

Nanotechnology is an experimental field of applied science and technology. The prefix 'nano' means dwarf or extremely small. Nanoscience and nanotechnology are the recent revolutionary development in science and engineering that are evolving at a very faster rate [1]. Nanotechnology is the study of controlling the matter on an atom and molecular scale. It deals with structures between 1 to $100 \mathrm{~nm}$ in at least one dimension and it involves in modifying or developing materials within that size. Soil, a dynamic living matrix, is an essential and important part of the ecosystem, i.e. terrestrial ecosystem. Concerning plant growth and development; soil can be distinguished into two types, namely, rhizosphere soil and nonrhizosphere soil. The rhizosphere is the narrow region of soil immediately surrounding the plant roots. Our main focus was on the non-rhizosphere soil. The non-rhizosphere soil is also called as bulk soil, which is free from plant roots and is not a part of rhizosphere soil [2]. Microorganisms are universally present in air, soil, and water and play an important role in restoring the physical, chemical and biological properties of soil. Their role in agriculture is vital for nitrogen fixation, phosphate solubilisation, and mobilization of nutrients. Such beneficial microbes are called bio-fertilizers, which include both free-living and symbiotic forms [3].

Silver nanoparticles (AgNPs) have attracted increasing interest due to chemical stability, catalytic activity, and high conductivity. Based on their good antimicrobial function and toxicity; the AgNPs have been used as an effective typical application for improving wound healing. Wang and co-workers in 2016 studied the influence of
AgNPs in an animal model of wound healing by using silver sulfadiazine as a control [4]. The biosynthesized nanoparticles have used in a variety of applications, including drug carriers for targeted delivery, cancer treatment, gene therapy, DNA analysis, antibacterial agents, biosensors, enhancing reaction rates, separation science, and magnetic resonance imaging, etc. AgNPs show effective antimicrobial activity against gram-positive bacteria including highly multidrug-resistant strains such as methicillin-resistant Staphylococcus aureus [5]. Recently, scientists have made efforts to make use of microorganisms as possible eco-friendly nano factories for the synthesis of AgNPs because various microbes are known to reduce the $\mathrm{Ag}^{+}$ion to form AgNPs [6].

Synthesis of AgNPs by microbes is due to their defense mechanism and this is how the nanoparticles produced are useful to us. Studies have found that many microorganisms can produce inorganic nanoparticles either through intercellular or extracellular routes. The resistance caused by the bacterial cell for silver ions in the environment is responsible for its nanoparticle synthesis [7]. The silver ions $\left(\mathrm{Ag}^{+}\right)$in nature are highly toxic for bacterial cells; therefore, their cellular machinery helps in the conversion of reactive silver ions into stable silver atoms $\left(\mathrm{Ag}{ }^{\circ}\right)$. Also, the temperature and $\mathrm{pH}$ play an important role in their production. At room temperature; the size of nanoparticles is $50 \mathrm{~nm}$, at a higher temperature (i.e. 60 [) the size of nanoparticles reduces to $15 \mathrm{~nm}$. This indicates that with the increase in temperature; size decreases [8]. Under alkaline conditions, nanoparticles synthesized by the microbes are more as compared to acidic conditions. Most antibiotics that are very potentially active against free microbes are 
less effective against the same species when present as a biofilm This is a particular concern because microbial biofilms play a vital role in many infections, and biofilm-related traits may confer highlevel antibiotic resistance in microbial communities [9].

The present work was undertaken to isolate a potent bacteria from a diverse source of soil samples from Tiwac fields, Dharwad. To elucidate their biological activities like antibacterial activity against various pathogenic bacteria and various characterizations like UVVisible spectroscopy, AFM, TEM, SEM with EDX, X-ray Diffraction, FTIR, and HR-TEM. The molecular characterization of the Strain NS24 was done by $16 \mathrm{~S}$ rRNA gene sequencing.

\section{MATERIALS AND METHODS}

\section{Soil samples, chemicals, and microbial cultures collection}

The soil samples were collected from Tiwac, Dharwad, Karnataka, India. The chemicals such as Silver nitrate $\left(\mathrm{AgNO}_{3}\right.$, Sigma Aldrich) and Nutrient agar (NA) medium were procured from Hi-media laboratories. Bacterial cultures such as Enterococcus faecalis (MTCC 6845), Escherichia coli (MTCC 40), Streptococcus pneumoniae (MTCC 8874) and Staphylococcus aureus (MTCC 2825) were procured from IMTECH Chandigarh, India.

\section{Isolation of bacteria}

To isolate the bacteria, the normal form of the serial dilution plate culture method was used. Soil samples were air-dried for 2 to $3 \mathrm{~d}$ before isolation. The soil suspension method described previously was followed [10] and $100 \mu$ l of soil suspension was spread on NA poured Petri plates. Later, the plates were incubated at $37^{\circ} \mathrm{C}$ for 1 to $2 \mathrm{~d}$ [11]. Twenty four bacterial isolates were obtained and among these isolated bacteria, only one bacterium was found gramnegative. The gram-negative bacterium was designated as Strain NS24 and was taken for further analysis.

\section{Synthesis of AgNPs}

For the synthesis of AgNPs, the Strain NS-24 was grown in $500 \mathrm{ml}$ conical flasks containing $250 \mathrm{ml}$ of Nutrient broth and the culture was grown with continuous shaking on a rotary shaker $(120 \mathrm{rpm})$ at $30{ }^{\circ} \mathrm{C}$ for $3 \mathrm{~d}$. After $3 \mathrm{~d}$ of incubation, the bacterial mass was separated by centrifugation at $12000 \mathrm{rpm}$ for $20 \mathrm{~min}$ and the collected cell-free supernatant was interacted with an equal volume of $1 \mathrm{mmol} / \mathrm{l}$ aqueous $\mathrm{AgNO}_{3}$ solution at $\mathrm{pH}$ 8.0. The interacted solution was kept on a rotary shaker at $30{ }^{\circ} \mathrm{C}(120 \mathrm{rpm})$ and maintained in the dark for $4 \mathrm{~d}$ [12].

\section{Characterizations of AgNPs synthesized from Strain NS-24}

\section{UV-visible Spectroscopy}

The UV-visible absorption of biologically synthesized AgNPs was measured by a sampling of the mixture and absorption maxima at 200 $\mathrm{nm}$ to $700 \mathrm{~nm}$ by UV-visible spectrophotometer (METASH UV-9000) at USIC, Karnatak University, Dharwad. A spectrum of AgNPs was plotted with a wavelength on X-axis against absorbance on Y-axis [13].

\section{Atomic Force Microscopy (AFM)}

Atomic force microscopy work was carried out to study morphology, size, and distribution of AgNPs. Purified suspension mixture was freeze-dried to obtain a dry powder. A very thin film of the nanoparticles was prepared on a glass slide and it was allowed to dry for $2 \mathrm{~h}$. Further, the slides were scanned with the AFM instrument (Nano surf Flex AFM) at USIC, Karnatak University, Dharwad [14].

\section{Scanning Electron Microscopy (SEM) with EDX}

Scanning Electron Microscopy (SEM) work was carried out to study morphology, shape, size, and nature of distribution whereas, the elemental analysis of AgNPs was done using Energy Dispersive Spectroscopy (EDS) coupled with SEM. Purified suspension mixture of AgNPs was freeze-dried to obtain a dry powder. A very thin film of the AgNPs sample was prepared on the SEM stab and kept it for gold coating. Later, the sample was scanned with the SEM instrument (JSM-IT 500LA) for studies on morphology and elemental mapping of AgNPs [15].

\section{X-ray Diffraction (XRD)}

The identification of the crystalline structure of the AgNPs was performed by Rigaku Miniflex 600, X-ray Diffractometry (XRD) analysis. The AgNPs powder was placed into the sample holder and a smooth surface was made through pressing. The XRD spectra were recorded between $30^{\circ}$ and $80^{\circ}$ by X-ray diffractometer equipped with $\mathrm{CuK} \alpha$ filter $(\lambda=0.15418 \mathrm{~nm}), 2 \theta / \theta$ scanning mode. The obtained diffractogram was compared to the standard JCPDS card No. 04-0783. The size of AgNPs was estimated using Scherr's formula, $d=0.89 \lambda / \beta \cos \theta[16]$.

\section{Fourier Transform Infrared (FTIR) Spectroscopy}

The FTIR spectroscopy work was carried out to study of possible biological functional groups involved in the synthesis and stabilization of biological AgNPs. The FTIR spectra were recorded in the range of $400 \mathrm{~cm}^{-1}$ to $4000 \mathrm{~cm}^{-1}$ using a Nicolet 6700 FTIR spectrophotometer. The various modes of vibrations were analyzed to determine the different biological functional groups present in the AgNPs [14].

\section{HR-TEM}

The High Resolution-Transmission electron microscopy (HR-TEM) analysis was used to visualize and calculate the morphology and size of AgNPs. The powder of AgNPs was diluted with sterile distilled water and applied onto a carbon-coated copper TEM grid. This was allowed to dry at room temperature for 15 min under infrared light and was further photographed at a magnification of $60000 \mathrm{X}$ to $80000 \mathrm{X}$ and a size scale range of 50 to $200 \mathrm{~nm}$ [13].

\section{Molecular characterization of Strain NS-24}

The genomic DNA was extracted from the fresh culture of the Strain NS-24. The 16S rRNA genes were amplified using primers. The following conditions were programmed for the amplification of genomic DNA using PCR. The chain reaction was scheduled as initial denaturation of 25 cycles at $96^{\circ} \mathrm{C}$ for $5 \mathrm{~min}$, denaturation at $96{ }^{\circ} \mathrm{C}$ for $30 \mathrm{~s}$, hybridization at $50{ }^{\circ} \mathrm{C}$ for $30 \mathrm{~s}$ and final extension $60^{\circ} \mathrm{C}$ for 1:30 min. The obtained PCR products were electrophoresed on $1 \%$ agarose gel, where 500 base pairs DNA ladder was used for size reference. The electrophoresed amplicons were purified and later, sequenced using a Sanger Sequencing 3500 Series, Genetic Analyzer. The obtained gene sequence was interrogated in the NCBI database via the BLAST web portal. The DNA sequences were aligned and a phylogenetic tree was constructed by the Neighbour-joining method using the software MEGA7.0 [17].

\section{Biological activity of AgNPs}

\section{Antibacterial activity by agar well diffusion method}

The synthesized AgNPs were tested to check the potentiality against 4 human pathogenic bacteria through a well diffusion method. The pathogenic bacteria such as gram-negative Escherichia coli and gram-positive Staphylococcus aureus, Streptococcus pneumoniae and Enterococcus faecalis were collected from the microbial type culture collection (MTCC), Pune. For antibacterial activity, $1 \mathrm{mg}$ of AgNPs was mixed with $1 \mathrm{ml}$ of distilled water and used as a working solution. Each culture plates containing Muller-Hinton agar medium were swabbed with $100 \mu$ l of overnight grown pathogenic bacteria. The wells were made using a $6 \mathrm{~mm}$ cork borer and each well was loaded with different concentrations of AgNPs suspension; such as $25 \mu \mathrm{l}, 50 \mu \mathrm{l}, 75 \mu \mathrm{l}$, and $100 \mu \mathrm{l}$. All the plates were incubated at 37 ? for $18 \mathrm{~h}$ and then examined for the appearance of a clear area around the well. The zone of inhibition was measured in millimeters (mm) [18].

\section{RESULTS AND DISCUSSION}

Totally eight soil samples were collected from the fields of Tiwac, Dharwad, Karnataka, India and were used for the isolation of Bacteria. The collected samples were air-dried for 2 to $3 \mathrm{~d}$ before isolation to make it free from moisture and these samples were preserved to obtain better qualitative isolates of Bacteria. A total of twenty-four aerobic bacterial strains were isolated on NA medium at $37{ }^{\circ} \mathrm{C}$. The bacterial Strain NS-24 was chosen based on its gramnegative nature. The gram-negative bacteria have a thick 
peptidoglycan layer in the cell wall and establish a resistance to a big range of antibiotics. Therefore, the gram-negative isolate NS-24 was chosen for the synthesis of AgNPs.

\section{Characterization of synthesized AgNPs from Strain NS-24}

\section{UV-visible spectrophotometric analysis}

The UV spectral data of the biological synthesized AgNPs were analyzed by mixing colorless supernatant of the Strain NS-24 (fig. $1 \mathrm{~A}$ ) and an equal volume of aqueous $\mathrm{AgNO}_{3}$ solution. After $4 \mathrm{~d}$ of incubation, the mixture turned dark brown in color at $\mathrm{pH} 8.0$ (fig.
1B). The change of color indicated the formation of AgNPs, which might be due to the excitation of surface plasmon vibrations with the biological AgNPs. A similar result was reported in the literature, where Carica papaya leaf extract color was changed from light yellow to yellowish-brown while adding $\mathrm{AgNO}_{3}$ solution. [20]. The synthesis of AgNPs was further confirmed by measuring the wavelength using a UV-Vis. Spectrophotometer at a range of $200 \mathrm{~nm}$ to $700 \mathrm{~nm}$. The synthesized AgNPs exhibited a maximum UV absorption at $423 \mathrm{~nm}$ at pH 8.0 (fig. 2). This was confirmed with the results of Hina et al., (2018) [21], where Pseudomonas sp. synthesized AgNPs attained an absorption peak at $412 \mathrm{~nm}$.

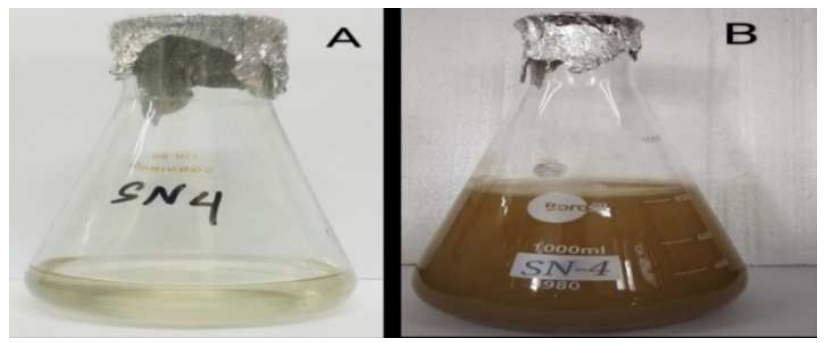

Fig. 1: Synthesis of silver nanoparticles from Strain NS-24: (A) Strain NS-24 supernatant before the addition of $\mathrm{AgNO}_{3}$, (Colorless), (B) Strain NS-24 supernatant after addition of $\mathrm{AgNO}_{3}$, (Brown)

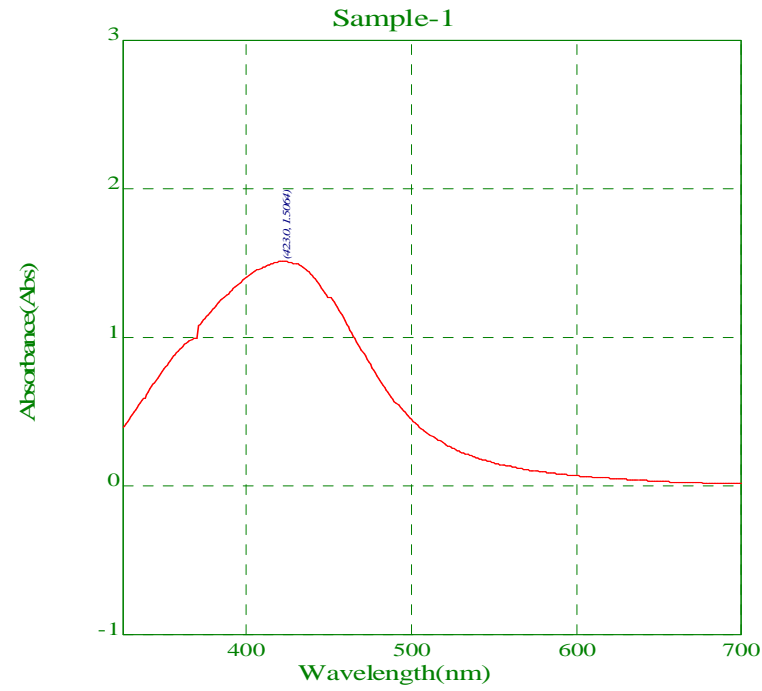

Fig. 2: UV-spectrum of synthesized AgNPs from Strain NS-24

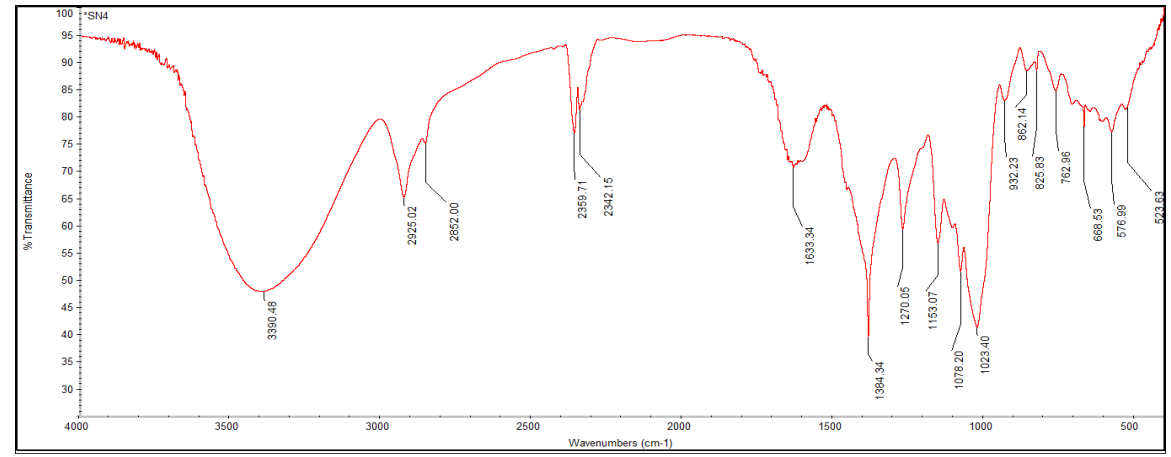

Fig. 3: FTIR spectrum of synthesized AgNPs from Strain NS-24

\section{FTIR analysis of AgNPs}

The FTIR spectrum of the Strain NS-24 synthesized AgNPs were used to determine the functional groups by active components based on the peak values in the region of infrared radiation, as shown in fig. 3 and table 1. This result was compared with the similar results of Fatima et al., (2017) [11]. Till today; the proper mechanism for synthesis of AgNPs is not perceived totally. However, it is well understood that AgNPs are 
synthesized through a reduction pathway with the help of enzymes. The enzymes present in the reaction mixture reduce the silver ions $\left(\mathrm{Ag}^{+}\right)$to metallic silver $\left(\mathrm{Ag}^{\circ}\right)$. Hypothetically, it is assumed that; the bio- chemicals such as alkaloids, proteins, tannins, flavonoids, terpenoids, sterols, etc., present in the reaction mixture act as reducing agent and capping agents, thereby synthesize the AgNPs.

Table 1: FTIR absorption peaks and their associated functional groups present in Strain NS-24 synthesized AgNPs

\begin{tabular}{ll}
\hline Absorption peak (cm-1) & Functional groups \\
\hline 3390 & Dimer O-H Stretch \\
2852 & -CHO \\
2359 & P-H Phosphine Stretching \\
2025 & -N=C=S Stretching (Isothiocyanate) \\
1633 & C=N Stretching (imine/oxime) \\
1384 & S=O (sulfate) stretching \\
1270 & C-H Wag (alkyl halide) \\
1163 & C-N Stretch (Amines) \\
1078 & P-H bending (Misc.) \\
1023 & C-O Stretch(Carboxylic acid)/C-O Stretch(Esters) \\
923 & RCOOH O-H Bending (Carboxylic acid) \\
862 & C-H Stretch (1,2,4,5,Tri-substituted aromatics) \\
826 & C-H Stretch (Para-di-substituted aromatics) \\
762 & C-H Stretch (Tri-sub. Aromatics) \\
668 & C-Br Stretch Alkyl halides \\
523 & S-S Disulphide Asymmetric Stretch \\
\hline
\end{tabular}

\section{AFM analysis of AgNPs}

The morphology and size of nanoparticles were ascertained from the AFM images. AFM data revealed that the size ranged from 12 $\mathrm{nm}$ to $79 \mathrm{~nm}$ (fig. 4A) in two and three-dimensional structures of the nanoparticles with a height of $14.4 \mathrm{~nm}$ (fig. 4B). The distance from each other was $51.17 \mathrm{~nm}$ (fig. 4C). A two or threedimensional horizontal cross-section of the AgNPs indicated that the biological AgNPs were well defined, polydispersed and spherical in shapes and between $12 \mathrm{~nm}$ to $79 \mathrm{~nm}$ in size. This result was compared with the finding of Bramhaiah and Neena (2013) [22].
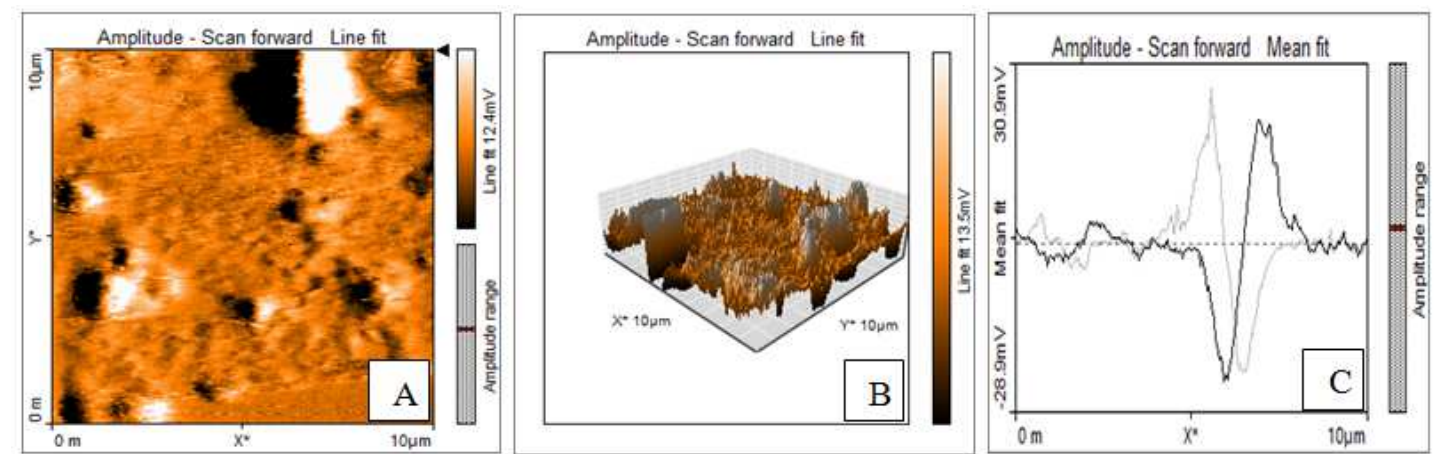

Fig. 4: AFM analysis of synthesized AgNPs (A) Two-dimensional structure of AgNPs, (B) Three-dimensional structure of AgNPs, and (C) Particle size distribution

\section{HR-TEM analysis AgNPs}

The bio-reduced AgNPs were elucidated with the help of HR-TEM to determine the shape and size of AgNPs. TEM images of AgNPs derived from the Strain NS-24 shown in fig. 5. The TEM images of AgNPs at various magnifications confirmed as non-agglomerated and spherical in shape (fig. $5 \mathrm{~A}$ ). Formed nanoparticles were in the range of 12.56 to 27.32 $\mathrm{nm}$ in size (fig. 5B) and were polydispersed in nature (at $20 \mu \mathrm{m}$ magnification). A similar result was observed by Ederley et al., (2018) [23], where the scientists synthesized AgNPs from Aloe vera plant extract. The HR-TEM analysis measured the particle size in the range of 2 to $14 \mathrm{~nm}$ for ethanolic and aqueous extracts. In another report, HR-TEM analysis of Acalypha indica mediated green synthesized AgNPs were found polydispersed with a particle size in the range of 20 to $40 \mathrm{~nm}$ [24].
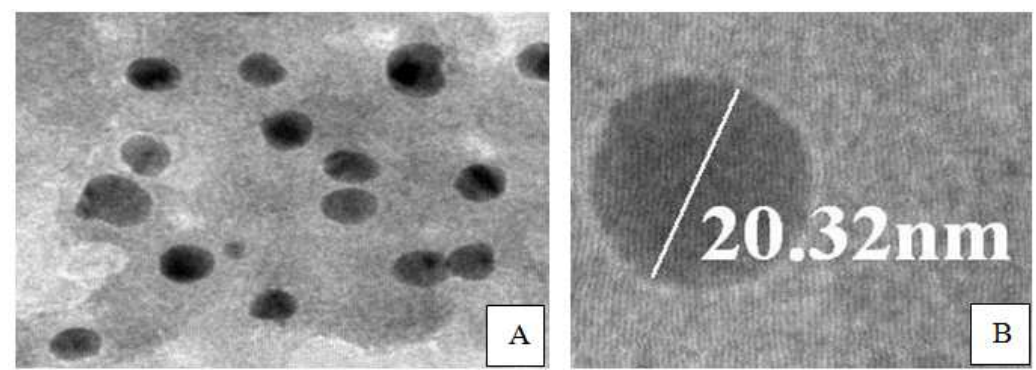

Fig. 5: TEM analysis of AgNPs (A) Spherical shaped AgNPs (B) The size of an AgNP (20.32 nm) (Magnification is $20 \mu \mathrm{m})$ 


\section{SEM with EDX for AgNPs}

SEM images showed that most of the AgNPs were predominately spherical, having a smooth surface and well dispersed with the close compact arrangement. The average particle size found to be around $17.49 \mathrm{~nm}$. The dispersive energy spectrum of the synthesized nanoparticles suggested the presence of silver as the ingredient element (fig. 6A). AgNPs generally showed a typically strong signal peak at $3 \mathrm{keV}$ due to surface plasmon resonance and it showed the quantitative information of biosynthesized AgNPs. Finally, all the microscopic studies revealed the biologically synthesized AgNPs were spherical in shapes, having the polydispersed and no agglomerations were found between the particles. The existence of elements such as $\mathrm{Ag}, \mathrm{O}, \mathrm{C}, \mathrm{K}, \mathrm{Cl}, \mathrm{Ca}$ and Na were shown in fig. 6B. The same sample was analyzed with the help of the EDX instrument showed $37.46 \%$ presence of carbon in the sample along with 26.72 $\%$ of oxygen, $1.25 \%$ of sodium, $0.68 \%$ of aluminum, $2.61 \%$ of chlorine and $31.28 \%$ of silver. Similar work was reported by Gitishree et al., (2019) [25], where the SEM analysis of Ananas comosus synthesized AgNPs revealed spherical structured nanoparticles and EDX spectra reported the $37.32 \%$ of silver of its total composition.
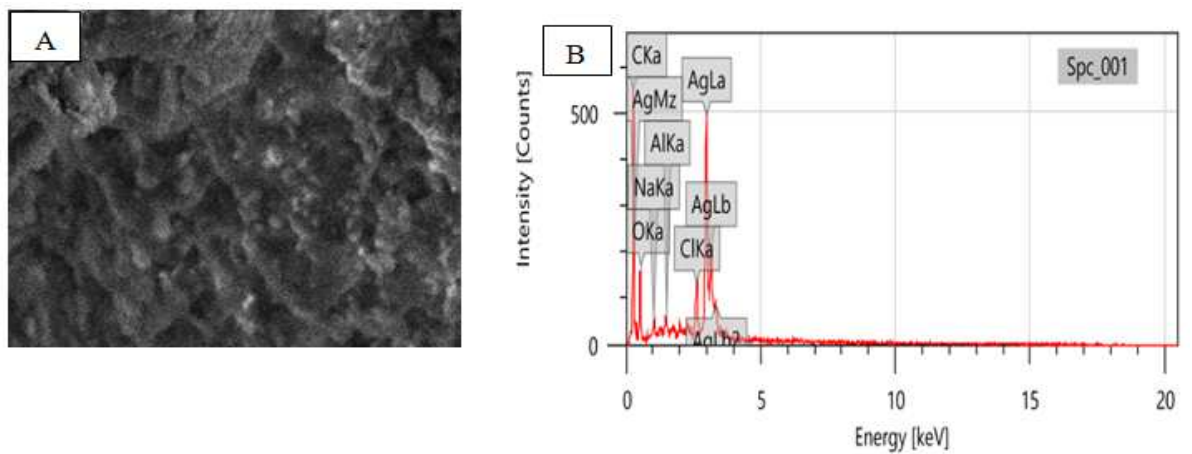

Fig. 6: SEM with EDX for AgNPs: (A) Morphology of AgNPs of the Strain NS-24 studied by SEM, (B) EDX element composition graph

\section{X-ray diffraction (XRD) spectroscopy analysis of AgNPs}

The phase purity and composition of AgNPs were examined by XRD in (fig. 7). The XRD spectrum showed five distinct diffraction peaks at $32.17^{\circ}, 46.17^{\circ}, 56.39^{\circ}, 66.30^{\circ}$ and $76.66^{\circ}$ corresponding lattice plane value was indexed at (111), (200), (220) and (311) planes of the face- centered cubic (FCC) silver, which were compared with the standard powder diffraction card of a joint committee on the powder diffraction standard (JCPDS). The average size of silver nanoparticles was found to be $18.57 \mathrm{~nm}$. A similar report was published by Khan et al., (2017) [26], where average $29 \mathrm{~nm}$-sized AgNPs were obtained through the XRD spectra of Ocimum sanctum leaf broth.

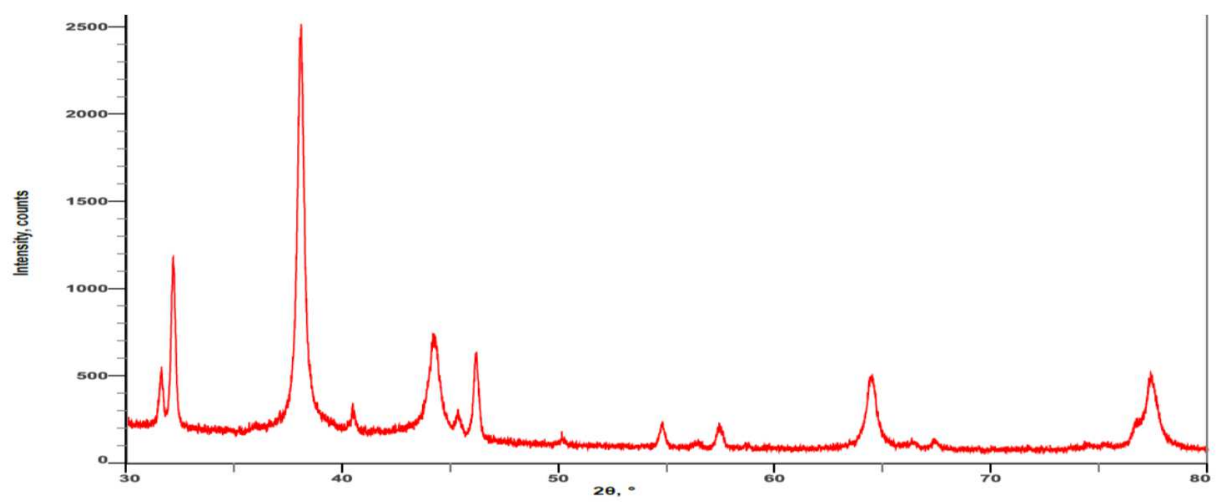

Fig. 7: XRD spectrum of synthesis of AgNPs synthesized from Strain NS-24

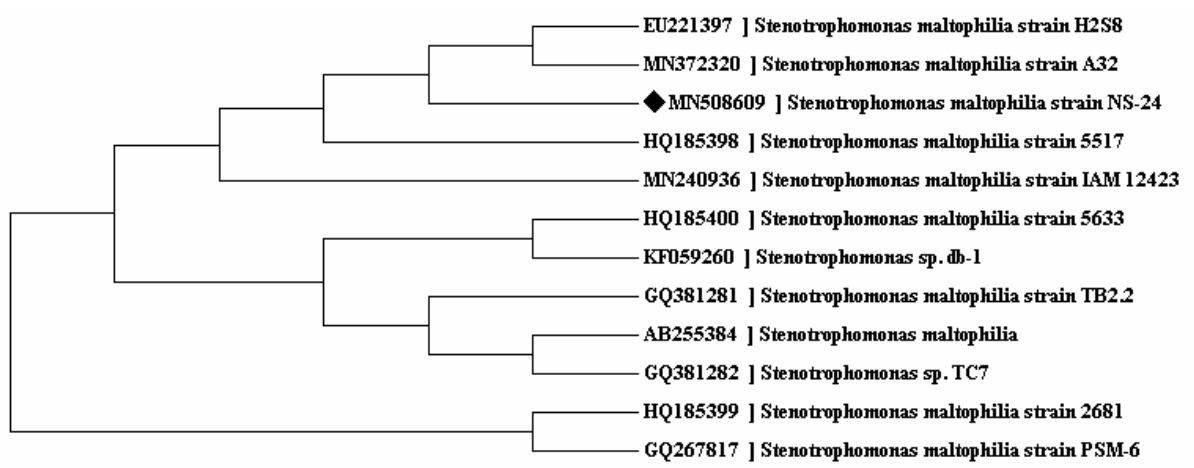

Fig. 8: Phylogenetic relationships of the Strain NS-24 based on 16S rRNA gene sequencing 


\section{Molecular characterization of Strain NS-24}

The molecular taxonomical identification of the Strain NS-24 was done by $16 \mathrm{~S}$ rRNA gene sequencing. The genomic DNA was extracted and purified. The region of $16 \mathrm{~S}$ rRNA was amplified using PCR and two forward and reverse primers. The sequenced data obtained was 1533 base pair in length and was deposited in Gene Bank with accession number MN508609. The gene sequence was later compiled and matched with the Gene bank database using the Basic Local Alignment Search Tool (BLAST) on the NCBI website. The alignment of DNA sequence was done and a phylogenetic tree was constructed by the neighbor-joining method using MEGA7.0 software (fig. 8). The analysis of the phylogenetic tree the Strain NS24 revealed a $98 \%$ sequence similarity to the Stenotrophomonas maltophilia strain A32 (MN372320). This can be compared with the results, where the 16S rRNA gene sequencing of strain B5 revealed 99\% sequence similarity with Bacillus amyloliquefaciens (KM384034) [27].

\section{Biological activity of AgNPs}

\section{Antibacterial activity}

The antibacterial activity of biologically synthesized AgNPs was studied on four different gram-positive and gram-negative pathogenic bacteria like Escherichia coli, Enterococcus faecalis, Streptococcus pneumoniae and Staphylococcus aureus. The zone of inhibition formed at different concentrations of AgNPs against different microorganisms was measured (table 2). The zone of inhibition caused by AgNPs of various concentrations like $25 \mu \mathrm{l}, 50$ $\mu \mathrm{l}, 75 \mu \mathrm{l}$, and $100 \mu \mathrm{l}$ was measured. The synthesized AgNPs showed good antibacterial activity against the selected pathogenic bacteria. Among the bacterial pathogens, E. faecalis and S. pneumoniae were found to be more sensitive to the AgNPs synthesized from the Strain NS-24 and E. coli was the least sensitive. The inhibition zones formed by the AgNPs against the bacterial pathogens at different concentrations were shown in (fig. 9). It has been observed that the biogenic AgNPs exhibited relatively high antibacterial activity against gram-positive and gram-negative bacteria as compared to that of controls (Strain NS-24 supernatant and $\mathrm{AgNO}_{3}$ solution). The primary screening was used to select the antimicrobial isolates and determine the range of microorganisms that were inhibited to Strain NS-24 synthesized AgNPs. Depending on the result of antimicrobial activity by well diffusion method; the Strain NS-24 synthesized AgNPs showed good inhibition zone against four pathogenic organisms during the assessment of biological activity. Our results were in confirmative with the reports described by Remya et al., (2018) [28].

Table 2: Zone of inhibition formed at different concentrations of Strain NS-24 synthesized AgNPs against four different microorganisms (values were mentioned in mean \pm standard deviation, $n=3$ )

\begin{tabular}{|c|c|c|c|c|c|c|c|c|c|c|c|c|}
\hline \multirow[t]{2}{*}{ Microorganisms } & \multicolumn{8}{|c|}{ Zone of inhibition (mm) formed by AgNPs (1 mg/ml) } & \multirow{2}{*}{$\begin{array}{l}\operatorname{AgNO}_{3} \\
(100 \mu \mathrm{l}) \\
(\mathrm{mm})\end{array}$} & \multirow{2}{*}{$\begin{array}{l}\text { ( } \pm \\
\text { SD) }\end{array}$} & \multirow{2}{*}{$\begin{array}{l}\text { Strain NS-24 } \\
\text { supernatant } \\
(100 \mu \mathrm{l}) \\
(\mathrm{mm}) \\
\end{array}$} & \multirow{2}{*}{$\begin{array}{l} \pm \\
\text { SD) }\end{array}$} \\
\hline & $25 \mu \mathrm{l}$ & $\begin{array}{l}\text { ( } \pm \\
\text { SD) }\end{array}$ & $\begin{array}{l}50 \\
\mu l\end{array}$ & $\begin{array}{l}\text { ( } \pm \\
\text { SD) }\end{array}$ & $75 \mu \mathrm{l}$ & $\begin{array}{l}\text { (士 } \\
\text { SD) }\end{array}$ & $\begin{array}{l}100 \\
\mu l\end{array}$ & $\begin{array}{l}\text { (土 } \\
\text { SD) }\end{array}$ & & & & \\
\hline E. coli (MTCC 40) & 14.35 & \pm 1.0 & 16.6 & \pm 0.57 & 17.8 & \pm 0.76 & 20 & \pm 1.0 & 18.6 & \pm 0.45 & 15.4 & \pm 0.52 \\
\hline E. faecalis (MTCC 6845) & 17.23 & \pm 1.16 & 20.6 & \pm 0.5 & 21.26 & \pm 1.12 & 23.66 & \pm 0.28 & 15.8 & \pm 0.47 & 15.7 & \pm 0.39 \\
\hline $\begin{array}{l}\text { S. pneumoniae } \\
\text { (MTCC 8874) }\end{array}$ & 21.5 & \pm 0.5 & 22.4 & \pm 0.80 & 24.06 & \pm 0.90 & 27.4 & \pm 0.51 & 21.8 & \pm 0.28 & 17.5 & \pm 0.5 \\
\hline S. aureus (MTCC 2825) & 15.33 & \pm 0.57 & 17.5 & \pm 0.5 & 19.53 & \pm 0.50 & 23.53 & \pm 0.50 & 15 & \pm 1.0 & 15.3 & \pm 0.57 \\
\hline
\end{tabular}
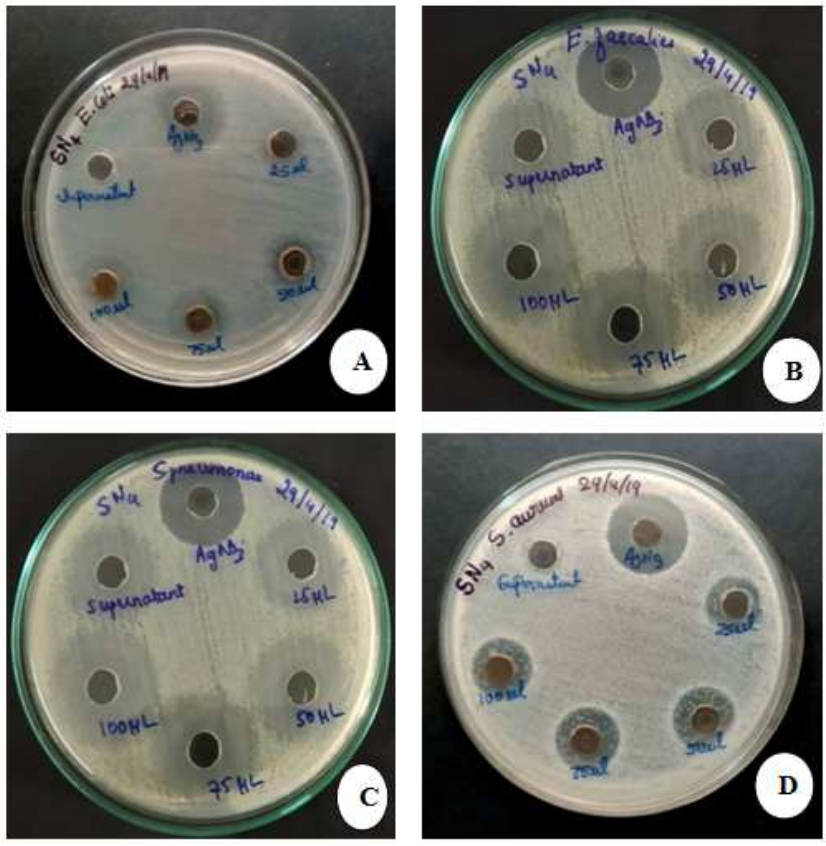

Fig. 9: Antibacterial activity result of biological AgNPs: (A) Escherichia coli (MTCC 40), (B) Enterococcus faecalis (MTCC 6845), (C) Streptococcus pneumoniae (MTCC 8874), (D) Staphylococcus aureus (MTCC 2825)

\section{CONCLUSION}

In this study, biological synthesis of AgNPs was successfully performed by bacterial supernatant. The AgNPs were synthesized from a gram-negative Strain NS-24 supernatant and characterized by various methods, like UV-visible spectra, AFM, TEM, SEM, EDX, Xray diffraction, FTIR, and HR-TEM. The molecular characterization of the Strain NS-24 was done by DNA extraction, 16S rRNA gene 
sequencing. The UV-visible spectrophotometric observation of AgNPs suspension showed maximum absorbance at $423 \mathrm{~nm}$. The AFM data confirmed that the particles were polydispersed and spherical in shapes. The FTIR analysis revealed the IR spectral band patterning and TEM analysis showed that the size of biological AgNPs was in the range of $12.56 \mathrm{~nm}$ to $27.32 \mathrm{~nm}$, with an average of $18.06 \mathrm{~nm}$ in size. The antimicrobial activity of AgNPs was studied on four different gram-negative and gram-positive bacterial strains like Escherichia coli, Enterococcus faecalis, Streptococcus pneumoniae, and Staphylococcus aureus for inhibition of their growth at varying concentrations of AgNPs. The biologically synthesized AgNPs showed broad-spectrum antimicrobial susceptibility against bacterial pathogens. Therefore, it is an eco-friendly, green, non-toxic, economical and rapid method for the synthesis of AgNPs and could be used as alternative sources of antibiotics for the management of pathogenic and multi-drug resistant microorganisms.

\section{ACKNOWLEDGMENT}

The authors were obliged to the UGC-SAP-DSA-I, India, Department of Studies in Botany, Karnatak University, Dharwad for providing financial support and the authors were also thankful to the University Science and Instrumentation Centre (USIC), Karnatak University, Dharwad for providing excellent infrastructure research facilities.

\section{AUTHORS CONTRIBUTIONS}

SN planned the research work and acquired the finance. PSS, MPB, and MR played out the sample collection and isolation of soil bacteria. BC, DA, played out the synthesis and characterizations of AgNPs and SKN and HH carried out the molecular characterization of NS-24. BC composed the manuscript. MR and DSB helped in the interpretation of results. All the writers read and endorsed the original copy.

\section{CONFLICTS OF INTERESTS}

Authors declare that there are no conflicts of interest between them.

\section{REFERENCES}

1. Gurujas K, Tanvir S, Amit K. Nanotechnology: a review. Int J Edu Appl Res 2012;2:50-3.

2. Ohalan GS, Sule IO, Garuba T, Salawu YA. Rhizosphere and nonrhizosphere soil Mycoflora of Corchorus olitorius (jute). Sci World J 2016;11:23-6.

3. Paula GF, Esther M, Raul R. Role of bacterial biofertilizers in agriculture and forestry. Bioeng 2015;2:183-205.

4. Azita DA, Mojtaba V, Rakhshani MH, Tofighian T. Comparison of the effect of nanosilver spray and 1\% silver sulfadiazine cream on the healing of second-degree burn wound. Transl Biomed 2018;9:1-6.

5. Guzman M, Dille J, Stephane G. Synthesis and antibacterial activity of silver nanoparticles against gram-positive and gramnegative bacteria. Nanomed Nanotechnol 2012;8:37-5.

6. Pravin V, Rosazlin A, Tumirah K, Salman I, Amru NB. Role of plant growth-promoting rhizobacteria in an agricultural sustainability-a review. Molecules 2016;21:573.

7. Simon S. Bacterial silver resistance: molecular biology and uses and misuses of silver compounds. FEMS Microbiol Rev 2003;27:341-53.

8. Gahlawat G, Anirban RC. A review on the biosynthesis of metal and metal salt nanoparticles by microbes. RSC Adv 2019;9:12944-67.

9. Penesyan A, Gillings M, Paulsen TI. Antibiotic discovery: combating bacterial resistance in cells and in biofilm communities. Molecules 2015;20:5286-98.

10. Ruangpan L, Tendencia EA. Bacterial isolation, identification and storage. In Laboratory manual of standardized methods for antimicrobial sensitivity tests for bacteria isolated from aquatic animals and the environment. Tigbauan, Iloilo, Philippines: Aquaculture Department, Southeast Asian Fisheries Development Center; 2004. p. 3-1.
11. Fatima MS, Aruna SS, Anbumalarmathi J, Umamaheswari K. Isolation, molecular characterization and identification of antibiotic-producing actinomycetes from soil samples. J Appl Pharm Sci 2017;7:69-5.

12. Sandhya M, Braj RS, Alim HN, Singh HB. Potential of biosynthesized silver nanoparticles using Stenotrophomonas sp. BHU-S7 (MTCC 5978) for the management of soil-borne and foliar phytopathogens. Sci Rep 2017;7:451-4.

13. Anbarasu A, Karnan P, Deepa N, Usha R. Carica papaya mediated green synthesized silver nanoparticles. Int J Curr Pharm Res 2018;10:15-20.

14. Lakshman G, Sathiyaselan A, Kalaichelvan PT, Murugsen K. Plant mediated synthesis of silver nanoparticles using fruit extract of Cleome viscose, assessment of their antibacterial and anticancer activity. Karbala Int J Mod Sci 2017;4:61-8.

15. Kumar SS, Venkateswarlu P, Rao VR, Rao GN. Synthesis, characterization and optical properties of zinc oxide nanoparticles. Int Nano Lett 2013;3:30.

16. Umoren SA, Obot IB, Gasem ZM. Green synthesis and characterization of silver nanoparticles using red apple (Malus domestica) fruit extract at room temperature. J Mater Environ Sci 2014;5:907-14.

17. Kumar S, Stecher G, Tamura K. MEGA7: molecular evolutionary genetics analysis version 7.0 for bigger datasets. Mol Biol Evol 2016;33:1870-4.

18. Okafor F, Janen A, Kukhtareva T, Edwards V, Curley M. Green synthesis of silver nanoparticles their characterization, application and antibacterial activity. Int J Environ Res Pub Health 2013;10:5221-38.

19. Das S, Banerjee C, Kundu A, Dey P, Saha H, Datta SK. Silica nanoparticles on front glass for efficiency enhancement in superstrate-type amorphous silicon solar cells. J Phys D: Appl Phys 2013;46:1-10.

20. Sulochana K, Vikrant S, Sunil C, Jaya PY, Samander K. Antichikungunya activity of green synthesized silver nanoparticles using Carica papaya leaves in animal cell culture model. Asian J Pharm Clin Res 2019;12:170-4.

21. Hina S, Juan D, Priyanka S, Tae HY. Extracellular synthesis of silver nanoparticles by Pseudomonas sp. THG-LS1.4 and their antimicrobial application. J Pharm Anal 2018;8:258-64.

22. Bramhaiah K, Neena SJ. Hybrid films of reduced graphene oxide with noble metal nanoparticles generated at a liquid/liquid interface for applications in catalysis. RSC Adv 2013;3:7765-73.

23. Ederley V, Gloria C, Gladis M, Cesar H, Jaime 0, Oscar A. Silver nanoparticles obtained by aqueous or ethanolic Aloe vera extracts: an assessment of the antibacterial activity and mercury removal capability. J Nanomater 2018:1-7. https://doi.org/10.1155/2018/7215210

24. Soumya M, Happy A, Rajesh KS, Venkat KS. Green synthesis of silver nanoparticles using medicinal plant acalypha indica leaf extracts and its application as an antioxidant and antimicrobial agent against foodborne pathogens. Int J Appl Pharm 2017;9:42-50.

25. Gitishree D, Jayanta KP, Trishna D, Abuzar A, Han-seung S. Investigation of antioxidant, antibacterial, antidiabetic, and cytotoxicity potential of silver nanoparticles synthesized using the outer peel extract of Ananas comosus (L.). Plos One 2019;14:e0220950.

26. Khan MZH, Tarek FK, Nuzat M, Momin MA, Hasan MR. Rapid biological synthesis of silver nanoparticles from Ocimum sanctum and their characterization. J Nanosci 2017:1-6. https://doi.org/10.1155/2017/1693416.

27. Ipsita D, Mrunmaya KP, Chandi CR. In vitro antimicrobial activity and molecular characterization of Bacillus Amyloliquefaciens isolated from similipal biosphere reserve, Odisha, India. Asian J Pharm Clin Res 2019;12:164-9.

28. Remya V, Priya VK, Priya R, Ajay VR, Aastha D. Silver nanoparticles green synthesis: a mini-review. Chem Int 2018;3:165-71. 